\title{
Review: The epic journey of sperm through the female reproductive tract
}

\author{
D. J. Miller ${ }^{\dagger}$ \\ Department of Animal Sciences, University of Illinois at Urbana-Champaign, 1207 West Gregory Drive, Urbana, IL 61801, USA
}

(Received 22 December 2017; Accepted 20 February 2018; First published online 19 March 2018)

\begin{abstract}
Millions or billions of sperm are deposited by artificial insemination or natural mating into the cow reproductive tract but only a few arrive at the site of fertilization and only one fertilizes an oocyte. The remarkable journey that successful sperm take to reach an oocyte is long and tortuous, and includes movement through viscous fluid, avoiding dead ends and hostile immune cells. The privileged collection of sperm that complete this journey must pass selection steps in the vagina, cervix, uterus, utero-tubal junction and oviduct. In many locations in the female reproductive tract, sperm interact with the epithelium and the luminal fluid, which can affect sperm motility and function. Sperm must also be tolerated by the immune system of the female for an adequate time to allow fertilization to occur. This review emphasizes literature about cattle but also includes work in other species that emphasizes critical broad concepts. Although all parts of the female reproductive tract are reviewed, particular attention is given to the sperm destination, the oviduct.
\end{abstract}

Keywords: bovine, oviduct, cervix, uterus, sperm

\section{Implications}

Sperm interaction with the cow reproductive tract after semen deposition has a profound influence on pregnancy rates and provides perplexing fundamental questions that are unresolved despite considerable study. The fertilizing sperm are selected by the tract from the millions or billions of sperm deposited at mating or artificial insemination (Al). Successful sperm interact with luminal fluid and epithelia, while evading destruction by the immune system. They respond to rheotactic, chemical and adhesive stimuli to undergo functional changes and arrive at the site of fertilization. An understanding of how these processes are coordinated can improve in vitro fertilization success, contraception effectiveness, sperm lifespan in the oviduct, improved semen storage and fertility.

\section{Introduction}

Normally only one sperm fertilizes an oocyte despite that billions of sperm are deposited by natural mating into the vagina, or millions are deposited by $\mathrm{Al}$ into the uterus of a cow. The remarkable journey that successful sperm take to reach the oocyte is long and tortuous, filled with viscous fluid, dead ends and potentially hostile immune cells.

${ }^{\dagger}$ E-mail: djmille@illinois.edu
Rather than a simple race to get to the oocyte, there is much evidence that complex mechanisms influence sperm transport, immunological tolerance of sperm, sperm selection, sperm storage and release, all before actual fertilization. At steps along the way to the site of fertilization, sperm may interact with the fluid in which they are suspended and the epithelium lining the tract. The very dynamic process of sperm transport helps ensure that there is an appropriate number of fertile sperm at the site of fertilization so that the oocyte can be fertilized by only one sperm. This review considers sperm interaction with fluid in the reproductive tract as well as sperm adhesion to the epithelium. It also reviews how sperm, foreign cells in the female reproductive tract, are tolerated by the immune system. Although it emphasizes literature about cattle, concepts developed in other species are included.

\section{Sperm in the vagina and cervix}

Sperm are transported through the vagina, cervix and uterus to the oviduct where they can fertilize oocytes. In cattle and many other mammals, estrus occurs before ovulation so sperm are deposited in the female reproductive tract before ovulation. At normal copulation in cattle, semen is deposited in the cranial vagina. Vaginal fluid is the first luminal medium to which sperm are exposed after semen deposition. 
The acidic $\mathrm{pH}$ of the vagina makes it inhospitable for sperm, although buffers found in semen neutralize the local $\mathrm{pH}$. The cow produces a large volume of vaginal fluid and up to $100 \mathrm{ml}$ can accumulate (reviewed by Rutllant et al., 2005). The rheological properties of vaginal fluid appear to influence sperm motility characteristics, although fertilizing sperm may spend only a short time in the vagina (Rutllant et al., 2005).

It is likely that bovine sperm, like human sperm (Suarez and Pacey, 2006), that are candidates to fertilize oocytes enter the cervical canal quickly avoiding damage due to the low vaginal $\mathrm{pH}$. The cervix contains many folds and grooves that are filled with mucus. The mucus within the canal is a major barrier to sperm, particularly those that have abnormal motility (Katz et al., 1997). The composition and structure of cervical mucus changes near estrus, allowing sperm with normal motility to advance, typically through what have been called 'privileged paths' that are found in the grooves produced by folds that extend through the cervical canal (Mullins and Saacke, 1989). A microfluidic model has confirmed that sperm migration through these privileged paths is controlled by microgrooves and a gentle flow of fluid (Tung et al., 2015b).

Sperm are foreign cells and can induce an immune response in the cervix. In rabbits, neutrophil infiltration was observed within $30 \mathrm{~min}$ of mating (Tyler, 1977). Immunoglobulins IgG and IgA (Kutteh et al., 1996) and complement proteins have been detected in human cervical mucus (Mathur et al., 1988). Therefore, sperm retained in the cervix might be attacked by the immune system before moving into the uterus.

\section{Sperm in the uterus}

After natural mating, sperm move from the cervical canal into the uterus. In cattle, $\mathrm{Al}$ is used frequently. When performing $\mathrm{Al}$, the technician deposits semen directly into the uterine body, so sperm do not enter the vagina and cervix. Depositing sperm directly in the uterus reduces the number of sperm needed for routine Al to 10-20 million (Moore and Hasler, 2017). As few as two million sperm are often inseminated when using sperm separated based on their sex chromosome, a process used to bias the sex of offspring (DeJarnette et al., 2009). Experiments in which the uterotubal junction (UTJ) in heifers was ligated at various times after mating revealed that it took $6-8 \mathrm{~h}$ for sperm to move through the cervix and uterus to infiltrate the oviduct in numbers sufficient for oocyte fertilization (Wilmut and Hunter, 1984). Sperm are transported through the uterus with the aid of uterine smooth muscle contractions in the direction of the oviduct (Hawk, 1987). To measure fluid movement and uterine contractions, technetium-labeled albumin-macrospheres were deposited in the uterus of women. These macrospheres $(5-40 \mu \mathrm{m}$ diameter) could be detected by high-resolution ultrasound. They were transported from the uterus to the oviduct more rapidly in the late follicular phase (Kunz et al., 1996) which, along with other experiments, indicates that uterine contractions that transport sperm are under endocrine control. Further, this result demonstrates that materials in addition to sperm can move through the UTJ.

Sperm in the uterus of cattle and other species are retained in uterine glands in low numbers per gland (Hunter, 1995; Rijsselaere et al., 2004). Retention, at least in swine, is accomplished by sperm binding to uterine epithelial cells (Rath et al., 2016). Sperm attachment to uterine cells stimulates the production of both pro- and anti-inflammatory cytokines (Lovell and Getty, 1968). There is evidence that porcine sperm bind to sialic acid-containing glycans on the surface of uterine epithelial cells (Rath et al., 2016). For example, a sialic acid lectin that recognizes sialic acid binds to uterine epithelial cells and blocks sperm binding, in vitro. Although it is not clear whether many sperm in uterine glands move into the oviduct, the fate of the majority of sperm in the uterus is elimination.

Rapid removal of sperm may help reduce the acquired immune response against sperm (Hansen, 2011). Little is known about the immune response elicited by semen deposition in cattle but it has been studied more in rodents and horses (Katila, 2012; Bromfield, 2014; Christoffersen and Troedsson, 2017). The primary function of the inflammatory response is to clear excess sperm, seminal debris and bacteria from the uterus. Following semen deposition, there is an infiltration of polymorphonuclear leukocytes (PMNs). In addition to activation of innate immunity, adaptive immunity is also involved. Several classes of antibodies have been isolated from uterine fluid. In addition to cytokines released from the uterine endometrium, seminal plasma itself contains immune system modulators that affect uterine and oviduct immune cells (Robertson, 2007; Schjenken and Robertson, 2014 and 2015). There is evidence that a seminal vesicle protein may allow the uterus to tolerate sperm (Kawano et al., 2014). Interestingly, the seminal fluid fraction of semen also improves preimplantation development and has interesting long-term effects on offspring (Bromfield et al., 2014). This non-traditional role of seminal plasma has been studied most in rodents; the amount of seminal plasma in cattle that mate normally is low and even lower when $\mathrm{Al}$ is used.

\section{Sperm entry into the oviduct through the utero-tubal junction}

In the bovine UTJ, sperm move through a slit-like lumen with a mucosal pad and into the lower portion of the oviduct, the isthmus, which contains four to eight primary grooves in tubal segment (Wrobel et al., 1993). Compared with the major part of the upper oviduct, the ampulla, the isthmus has a narrower lumen with fewer folds but a thicker layer of smooth muscle. Although macrospheres seem to have the ability to pass through the UTJ (discussed above), there is evidence that sperm, at least in mice, require a specific protein to be recognized and to pass through the UTJ into the isthmus. Mouse sperm deficient in ADAM3, due to mutation of the $A D A M 3$ gene or genes whose products affect ADAM3 
are not detected beyond the UTJ (Nakanishi et al., 2004; Yamaguchi et al., 2006; Yamaguchi et al., 2009; Okabe, 2013). Even if sperm from a chimeric male derived from a normal and a mutant embryo were deposited, only the normal sperm moved into the oviduct (Nakanishi et al., 2004). Thus, the presence of normal sperm does not aid in opening the UTJ to allow ADAM3 mutant sperm to pass into the oviduct.

In addition to ADAM3, there also appears to be a rheological barrier in the porcine UTJ, perhaps the viscous mucus present in the grooves of this structure (Hunter, 2002; Tienthai, 2015). The rabbit and mouse UTJ and oviduct fluid contain proteoglycans with sulfated glycosaminoglycan chains and hyaluronan (Jansen, 1978; Suarez et al., 1997). In addition to changing the viscosity and affecting sperm motility, the abundance of hyaluronan in fluid and its receptor, CD44 on the epithelial cells of the UTJ, suggest that CD44 signal transduction might affect the function of the UTJ and lower oviduct (Bergqvist et al., 2005a and 2005b).

In cattle and other species, there appears to be a valve at the UTJ that can constrict the lumen, restricting sperm entry. This valve is formed by a vascular plexus and surrounded by a thick muscle layer that, in total, can contract the lumen (Wrobel et al., 1993). The physical constriction, mucus barrier and protein signature requirements emphasize how stringently entrance to the oviduct is regulated.

\section{Sperm in the oviduct}

Once sperm enter the lower oviduct, the isthmus, they can bind to the epithelial cell surface or remain in oviduct fluid. Many studies of the intact oviduct have been performed in mice because the uterus and oviduct can be transilluminated so that sperm can be observed (Demott and Suarez, 1992). Sperm from transgenic mice that have enhanced green fluorescent protein in their acrosomes and red fluorescent protein in their midpiece mitochondria have been followed in the female tract after natural mating (La Spina et al., 2016). The location of live sperm and their acrosomal status can be followed using fluorescence microscopy.

When sperm in the lumen of the isthmus were observed, groups of sperm were carried by fluid that was moved alternately toward the uterus and then toward the ampulla (back and forth) by contractions of oviduct smooth muscle (Ishikawa et al., 2016). These contractions were not observed in the ampulla. Most of the sperm in the isthmus were acrosome-intact (La Spina et al., 2016). Relatively few sperm were found in the ampulla and most were acrosome-reacted (La Spina et al., 2016; Muro et al., 2016), consistent with the recent evidence that the acrosome reaction of fertilizing mouse sperm occurs before contact with the cumulus-0ocyte complex (Jin et al., 2011; La Spina et al., 2016).

\section{Oviduct fluid affects sperm function}

The fluid in the oviduct is highly viscous, unlike the culture medium in which studies of mammalian fertilization are usually performed. Fluid viscosity is often overlooked in studies of sperm function within the oviduct. More viscous fluid has more internal friction so the wake from a sperm swimming in viscous medium is relatively small compared with less viscous medium (Kirkman-Brown and Smith, 2011). Studies of human sperm demonstrate that resistance of the fluid to be moved results in a sperm tail with multiple bends while beating (Kirkman-Brown and Smith, 2011; Hyakutake et al., 2015). In contrast, in less viscous medium, the tail has fewer bends and, instead, remains mostly straight while simply swinging or flapping back and forth (Kirkman-Brown and Smith, 2011; Hyakutake et al., 2015). Consequently, in viscous fluid, a motile sperm will have less side-to-side movement (yaw) than in a standard viscosity medium (Kirkman-Brown and Smith, 2011). Sperm also tend to swim near and against solid surfaces, for example, epithelial walls or the corners of microchannels (Denissenko et al., 2012). Sperm that are close to the channel wall swim faster than those moving in the center of the channel (El-Sherry et al., 2014). Viscoelastic medium induces bovine sperm to swim in coordinated groups that may facilitate sperm migration (Tung et al., 2017). The majority of sperm orient their swimming so that they swim against the flow of medium when the flow rate is intermediate $(33-134 \mu \mathrm{m} / \mathrm{s}$ ) (Miki and Clapham, 2013; El-Sherry et al., 2014; Tung et al., 2015a). This appears to guide sperm upstream in oviduct fluid (Miki and Clapham, 2013). There is controversy about whether a signaling process in sperm aids in orienting sperm in the upstream direction or if sperm rheotaxis is a passive process (Miki and Clapham, 2013; Hyakutake et al., 2015).

Interestingly, the viscosity of oviduct fluid varies during the estrous cycle; tenacious mucus is found in the rabbit oviduct lumen at estrus and disappears after ovulation (Jansen, 1978). Most studies of sperm-oviduct interaction or fertilization have used standard culture medium and ignored its low viscosity, compared with oviduct fluid. A few have tried to recapitulate the viscosity of oviduct fluid by adding components like methylcellulose or polyvinylpyrrolidone to medium (Suarez and Dai, 1992; Alasmari et al., 2013; Gonzalez-Abreu et al., 2017). In addition to effects on normal motility, discussed above, physiological viscosity converts the wild thrashing motion and high yaw of hyperactivated sperm to motility with less yaw and a more forward movement (Suarez and Dai, 1992).

In addition to the rheological properties of oviduct fluid, specific components of oviduct fluid such as secreted proteins, proteoglycans and lipids may influence fertilization by affecting sperm function (Coy et al., 2010; Killian, 2011). This complex fluid can affect sperm before encountering the oocyte and during fertilization (Rodriguez-Martinez, 2007; Killian, 2011). For example, bovine sperm take up phospholipids that are abundant in oviduct fluid (Evans and Setchell, 1978; Killian et al., 1989). Oviduct fluid glutathione peroxidase, superoxide dismutase and catalase can protect bovine sperm from damage by reactive oxygen species that may otherwise reduce sperm viability and motility (Lapointe and Bilodeau, 2003). Proteoglycans found in oviduct fluid promote capacitation of bovine sperm through their 
glycosaminoglycan side chains (Parrish et al., 1989; Bergqvist et al., 2006).

Oviduct fluid components, for example, glycosaminoglycans, can also cause proteolysis or loss of sperm membrane proteins, including those that are implicated in sperm binding to the oviduct epithelium. The best studied of these proteins originate from accessory gland secretions and bind to sperm at ejaculation. Some bovine Binder of Sperm (BSPs) and porcine sperm adhesins are lost as sperm are capacitated (Topfer-Petersen et al., 2008; Hung and Suarez, 2010). Although the significance of protein loss or proteolysis is uncertain, in sperm bound to the oviduct epithelium, it might contribute to their release before fertilization (Topfer-Petersen et al., 2008; Hung and Suarez, 2010).

In addition to losing proteins, sperm also gain proteins while they reside in the oviduct. The first of two examples is oviduct-specific glycoprotein (OGP) or oviductin, also known as OVGP1, found in oviducts of many mammals. Although it has homology to the chitinase family of proteins, OGP does not have enzymatic activity (Jaffe et al., 1996; Araki et al., 2003). Bovine sperm incubated in OGP have improved motility and viability (Abe et al., 1995). Hamster sperm treated with recombinant OGP have increased phosphorylation of tyrosine residues on proteins, an indication that capacitation was enhanced (Yang et al., 2015). There is also evidence in mice and swine that OGP binds to the zona pellucida to increase fertilization success by rendering the zona matrix more permissive to penetration by sperm (Lyng and Shur, 2009; Algarra et al., 2016).

A second example of an oviduct protein that affects sperm is osteopontin. Although it is already bound to bovine sperm before semen is deposited in females (Erikson et al., 2007), addition of osteopontin during in vitro fertilization reduces polyspermy (Goncalves et al., 2008). Neither osteopontin nor OGP is necessary for fertility in mice because animals deficient in each are fertile (Rittling et al., 1998; Araki et al., 2003).

In addition to oviduct fluid proteins being added as peripheral membrane proteins, integral membrane proteins could be added by fusion with sperm of oviductosomes secreted by the oviduct. For example, a portion of the major $\mathrm{Ca}^{2+}$ efflux pump is added to mouse sperm by oviduct exosomes (Al-Dossary et al., 2015). The proteins secreted by bovine oviduct cells and found in oviduct fluid have recently been profiled and include growth factors, metabolic regulators, immune modulators, enzymes and extracellular matrix components (Lamy et al., 2016; Pillai et al., 2017). They function in immune homeostasis, gamete maturation, fertilization and early development (Pillai et al., 2017). The abundance of some depend on the stage of the estrous cycle and whether they were found in oviducts ipsilateral or contralateral to the ovary that ovulated (Lamy et al., 2016).

\section{The oviduct as a functional sperm reservoir}

The oviduct, along with the UTJ in some species, appears to be the major location in which sperm are stored before fertilization. In contrast, although sperm are retained in the cervix or uterus, it is not clear that they are eventually released to move to the oviduct. So the UTJ and oviduct appear to be the major sperm storage sites in many mammals. To be a true 'functional sperm reservoir', as coined by Hunter et al. (1980), in addition to retaining sperm, the oviduct must affect sperm function and lengthen sperm lifespan beyond the inherent longevity of sperm (Orr and Zuk, 2014). More than simple adhesion occurs because binding to the oviduct epithelium prolongs the lifespan of sperm and suppresses capacitation and motility (Pollard et al., 1991; Rodriguez-Martinez et al., 2005; Rodriguez-Martinez, 2007; Hung and Suarez, 2010). Thus, the oviduct isthmus meets these requirements. However, the ability of sperm reservoirs described in a variety of species to prolong the lifespan of a highly differentiated and transcriptionally inactive cell is enigmatic.

The reservoir also releases a finite number of stored sperm, acting as a buffer for sperm number to prevent polyspermy but still provide an appropriate number of fertile sperm to the upper oviduct (Hunter and Leglise, 1971). The isthmic epithelium binds and retains preferentially sperm that have intact acrosomes and normal morphology (Teijeiro et al., 2011; Teijeiro and Marini, 2012). All together, the isthmus functions to increase the probability that a suitable number of fertile sperm are present at the site of fertilization.

\section{The oviduct epithelium retains sperm and modulates sperm function}

In mammals, the oviduct epithelium binds and retains sperm so they accumulate to form the reservoir. Adhesion is very specific. The sperm head binds to oviduct epithelial cells but not all cells (Pacey et al., 1995; Kervancioglu et al., 2000). Moreover, the ability of sperm binding to maintain viability is not a common property of all cells (Boilard et al., 2002). The ability to maintain viability requires direct contact between sperm and oviduct epithelial cells (Dobrinski et al., 1997; Murray and Smith, 1997; Smith and Nothnick, 1997). Adhesion to the oviduct regulates sperm capacitation (Dobrinski et al., 1997; Boilard et al., 2002; Fazeli et al., 2003) and suppresses the normal increase in sperm intracellular free calcium that occurs during capacitation (Dobrinski et al., 1996; Dobrinski et al., 1997).

Studies performed in several mammals have concluded that glycans are the components in oviduct epithelial cells that bind sperm (Lefebvre et al., 1997; Green et al., 2001; Suarez, 2001; Cortes et al., 2004; Topfer-Petersen et al., 2008). The evidence in most studies underpinning a role for oviduct glycans is a competition assay in which different glycans are added to sperm before challenging these sperm by allowing them to bind oviduct epithelial cells in vitro. If few sperm bind to oviduct cells, this result is interpreted as an indication that the specific glycan is related to the authentic oviduct glycan that binds sperm. A frequent problem with these studies is that most test high concentrations of a small number of monosaccharides or small oligosaccharides.

\section{Identification of glycans that bind porcine sperm using a glycan array}

The development of glycans immobilized on an array provided an opportunity to test hundreds of glycans for their 
ability to bind sperm. Using such an array, nearly 400 glycans were tested for their ability to bind porcine sperm (Kadirvel et al., 2012). All the glycans that bound sperm contained one of two glycan motifs, either a Lewis $X$ trisaccharide $\left(\mathrm{Le}^{\mathrm{X}}\right)$ or a structure with core mannose and two antennae terminating in the sialylated lactosamine trisaccharide bi-SiaLN or in simply lactosamine (Figure 1). There were several examples demonstrating that sperm bound these two motifs with high specificity. In all sialic acid-containing structures that bound sperm, sialic acid was linked to the 6 position of galactose; structures that were identical except that sialic acid was attached to galactose at the 3 position did not bind sperm. Furthermore, the branched structure on a mannose core was required because single sialylated lactosamine trisaccharides (Neu5Ac $\alpha 2-6$ Gal $\beta 1-4$ GlcNAc) did not bind sperm (Kadirvel et al., 2012).

The $L e^{\mathrm{X}}$ trisaccharide was found as a monomer, dimer or trimer in the remaining glycans that bound sperm (Kadirvel et al., 2012). This trisaccharide is composed of Gal and Fuc linked to GICNAC (Figure 1). The Le $\mathrm{X}^{\mathrm{x}}$ trisaccharide also bound sperm with high specificity; the closely related Lewis $A$ trisaccharide ( $\mathrm{Le}^{\mathrm{A}}$, a positional isomer; the carbons in GICNAC to which Gal and Fuc are linked are exchanged) did not bind porcine sperm. Contrarily, bovine sperm bind Le ${ }^{A}$ but not Le $\mathrm{X}^{\mathrm{X}}$ (Suarez et al., 1998). Binding specificity was further supported because porcine sperm did not bind to Gal $\beta 1$ 4GICNAc; fucose substitution on Le $\mathrm{x}^{\mathrm{x}}$ was necessary (Kadirvel et al., 2012).

To confirm that the glycans on the array that bound sperm were present in the oviduct isthmus and to determine the complete structures of the oviduct glycans that bound sperm, oviduct glycans and glycolipid structures were identified by tandem MS (Kadirvel et al., 2012). The Le $\mathrm{e}^{\mathrm{X}}$ and branched sialylated motifs (bi-SiaLN) that bound sperm were found on larger structures that were the most abundant of the complex-type glycans on epithelial cells (Kadirvel et al., 2012). Nearly all of the complex-type oligosaccharides linked to proteins through asparagine residues were branched with two antennae and several had a sialyl residue on at least one terminus. Some biantennary glycans had both motifs, a sialyl residue on one terminus and a Lewis structure on the second. This kind of hybrid glycan was not present on the array but it is possible that, because it includes both motifs, it might bind sperm with even higher affinity than glycans with a single motif.

As tandem MS did not distinguish between $\mathrm{Le}^{\mathrm{A}}$ and $\mathrm{Le}^{\mathrm{X}}$ and between glycans with sialyl residues attached to the 6-carbon and the 3-carbon of Gal, an additional strategy was used. An antibody and specific lectin, Sambucus nigra agglutinin were used that recognize sialic acid attached to galactose in an $\alpha-2,6$ linkage preferentially and not sialic acid attached to galactose in an $\alpha-2,3$ linkage (Naito et al., 2007; Song et al., 2011). Both reagents detected 6-sialylated structures that were abundant on the epithelium throughout the oviduct including on ciliated and non-ciliated cells (Kadirvel et al., 2012).

Similarly, an antibody to $\mathrm{Le}^{\mathrm{X}}$ was also used to confirm the identity of the oviduct Lewis trisaccharide structures identified by MS (Kadirvel et al., 2012). Interestingly, Le ${ }^{x}$ was found in a punctate pattern at the luminal surface of porcine isthmic epithelial cells (Machado et al., 2014) but was not found in the ampulla.

\section{bi-SiaLN and Le $e^{X}$ glycan motifs bind to the porcine sperm head}

The head is the portion of sperm that binds to the oviduct epithelium and is where (Suarez et al., 1991) authentic receptors for glycans with bi-SiaLN and/or Le $\mathrm{X}^{\mathrm{X}}$ motifs should be localized. Fluorescein-labeled $\mathrm{Le}^{\mathrm{X}}$ and bi-SiaLN bound preferentially to the apical edge of the head in 60\%-70\% sperm before capacitation (Kadirvel et al., 2012; Machado et al., 2014). Binding of fluoresceinated glycans could be displaced by an excess of the same glycan that did not have a fluorescent tag. The binding specificity was confirmed by

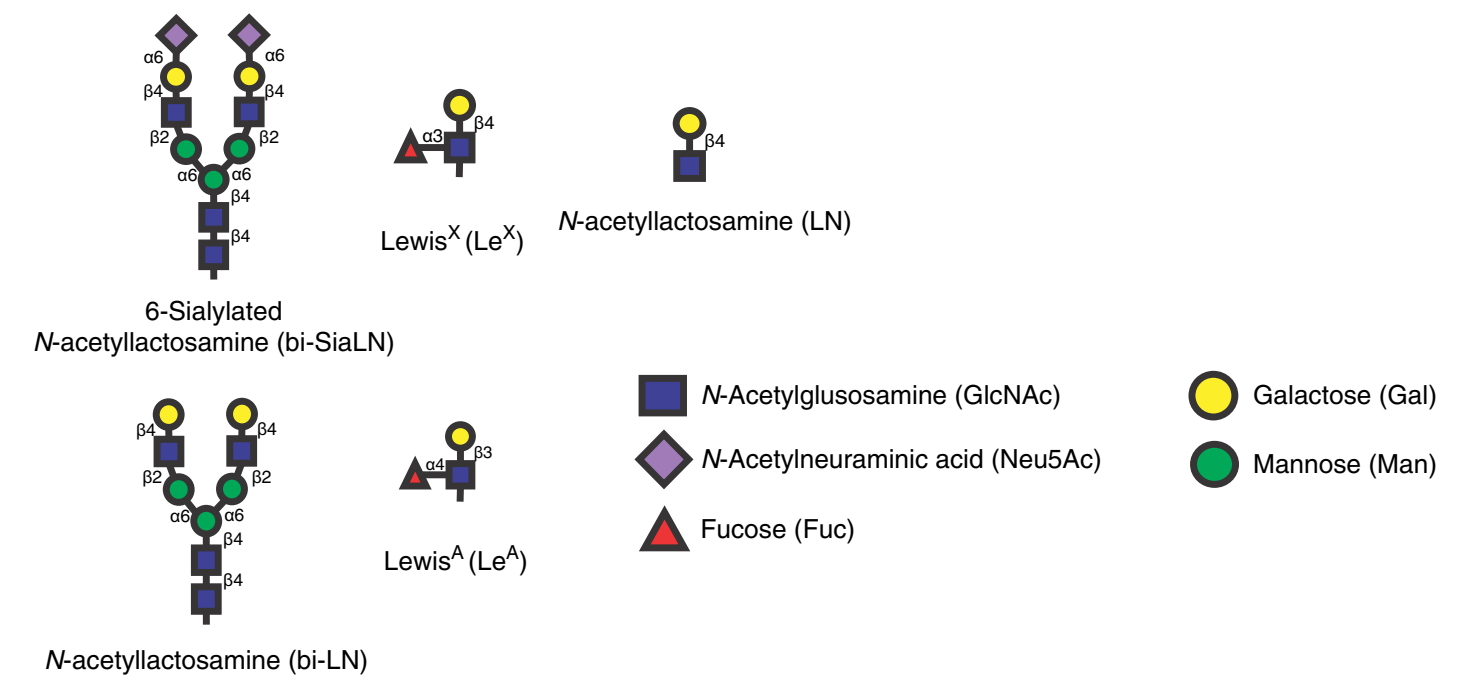

Figure 1 Structures of glycans that bind bovine ( $\mathrm{Le}^{\mathrm{A}}$ ) and porcine sperm (bi-SiaLN, bi-LN, and Le ${ }^{\mathrm{X}}$ ), and the related glycan that does not (LN). Le $\mathrm{A}^{\mathrm{A}}$ is found on the bovine oviduct epithelium. bi-SiaLN is abundant on the epithelium of the porcine ampulla and isthmus including ciliated and non-ciliated cells. $\mathrm{Le}^{\mathrm{X}}$ is found in the porcine isthmus but not the ampulla. 

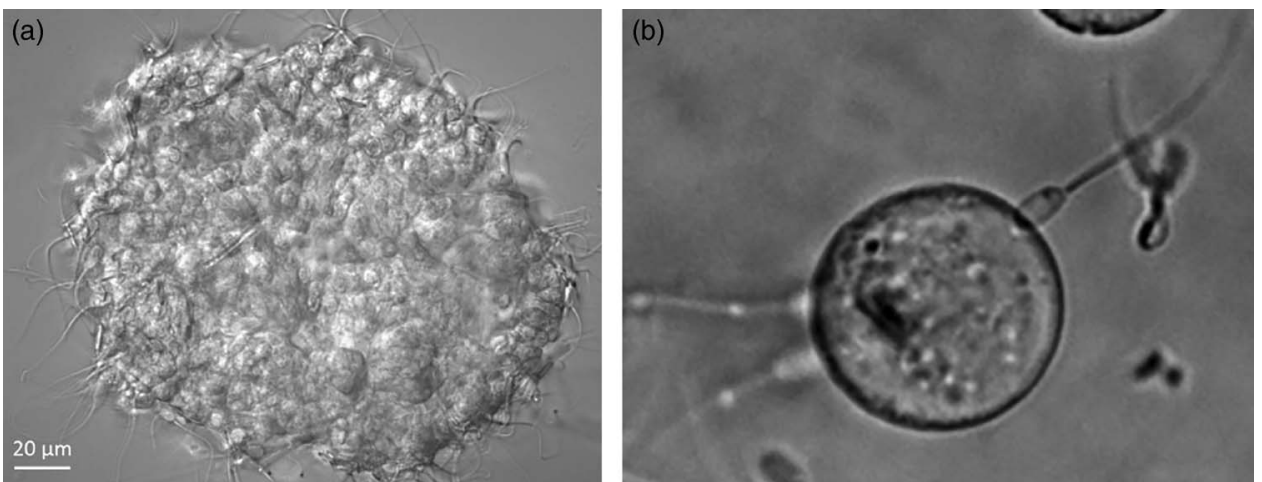

Figure 2 Sperm bind to oviduct cell aggregates isolated from the isthmus (a; porcine sperm) and beads to which Lewis $A$ (Le ${ }^{A}$ ) trisaccharide has been attached ( $b$; bovine sperm).

testing sperm binding to oviduct glycans attached to Sepharose beads (Figure 2). Tethering a motile cell to a solid phase glycan rather than a soluble glycan more closely mimics sperm binding to the oviduct and requires a higher affinity.

Porcine sperm binding to oviduct cells requires glycans with bi-SiaLN and $L e^{X}$

Experiments using immobilized glycans (i.e. the glycan array and glycans linked to Sepharose) showed that bi-SiaLN and $\mathrm{Le}^{\mathrm{X}}$ were each sufficient to tether a motile sperm. Necessity experiments were performed in which either the glycans or putative receptors were blocked. The result of blocking was assessed by sperm binding to aggregates of epithelial cells stripped from the isthmus (Figure 2). Results of these experiments indicated that each glycan or glycan receptor was necessary for sperm to bind oviduct cells.

\section{Receptors on sperm for oviduct glycans}

The identity of the receptors that bind oviduct glycans are controversial. Sperm from different species bind different glycans and the receptors they use may also be unique. Using bovine cells, one group provided evidence that two oviduct proteins, the chaperones GRP78 and HSP60, bound to sperm, although the glycans each bound were not determined (Boilard et al., 2004). A second group completed more detailed studies by and proposed that oviduct plasma membrane annexins containing fucose bind sperm proteins originating from accessory gland secretions added to sperm at ejaculation (Ignotz et al., 2007). This result was a bit surprising because annexins are usually considered cytosolic proteins and they lack signal peptides that would direct them through the secretory pathway to become fucosylated. A proteomic study found that annexin A1 is the most abundant protein in oviduct fluid (Lamy et al., 2016). Perhaps it is released into fluid without passing through the secretory pathway. However, in the fluid, it would be expected to compete with annexin A1 located on oviduct epithelial cells and decrease sperm binding to the oviduct.

Studies of porcine sperm also implicated accessory gland secretions added to sperm (Ekhlasi-Hundrieser et al., 2005; Topfer-Petersen et al., 2008). The spermadhesin AQN1 originating from accessory gland secretions is a glycan-binding protein (Ekhlasi-Hundrieser et al., 2005; Topfer-Petersen et al., 2008). Spermadhesins represent $90 \%$ of the total boar seminal plasma protein and they become peripherally associated with the sperm plasma membrane after ejaculation (Sanz et al., 1993). Sperm AQN1 is reported to bind mannose and galactose residues on oviduct cells, but not $\mathrm{Le}^{\mathrm{X}}$ or bi-SiaLN structures (Ekhlasi-Hundrieser et al., 2005).

The observation that the accessory gland proteins do not bind Le ${ }^{x}$ and bi-SiaLN motifs (Ekhlasi-Hundrieser et al., 2005) and sperm obtained from the cauda epididymis are still able to bind oviduct cells, although in reduced number (Petrunkina et al., 2001), suggested that other glycan receptors were important. Indeed, in cattle there is no evidence that the fertility of epididymal sperm, not exposed to accessory gland proteins, is lower that normal ejaculated semen that includes accessory gland secretions (Amann and Griel, 1974). The fertility of cauda epididymal sperm motivated the investigation of glycan receptors on porcine sperm from the epididymis, which also avoided interference from the very abundant accessory gland proteins (Silva et al., 2014).

Membrane lysates from porcine cauda epididymal sperm were separated chromatographically and each fraction was subjected to SDS-PAGE, transferred to nitrocellulose and incubated with biotinylated Le ${ }^{\mathrm{X}}$ and bi-SiaLN. This 'glycan blot' was used to identify proteins with appropriate glycan affinity. Several proteins were identified including the peripheral membrane protein MFG-E8, also known as lactadherin, P47 or SED1 (Silva et al., 2017). Competition experiments showed that lactadherin bound to oviduct cells and that inhibition reduced sperm binding (Silva et al., 2017).

Although there is compelling evidence that oviduct glycans are at least partially responsible for sperm binding, there is also evidence that sperm binding to oviduct epithelial cells is mediated to some degree by other interactions. Perturbation of glycans or their candidate receptors decreases sperm binding to oviduct cell aggregates by a maximum of 60\% (Kadirvel et al., 2012; Machado et al., 2014). Proteinbased interactions may account for the residual binding. For example, fibronectin from oviduct cells can bind $\alpha 5 \beta 1$ integrin on bovine sperm (Osycka-Salut et al., 2017) and the adhesion protein E-cadherin is found in both sperm and 
oviduct epithelial cells (Pollard et al., 1991; Lefebvre et al., 1995; Caballero et al., 2014).

\section{Oviduct epithelial cells respond to sperm binding}

In addition to the effect of adhesion on sperm, sperm adhesion to the oviduct modifies the transcriptional profile of oviduct epithelial cells (Fazeli et al., 2004; Georgiou et al., 2005; Georgiou et al., 2007; Lopez-Ubeda et al., 2015). Genes related to the inflammatory response, molecular transport, protein trafficking and cell-to-cell signaling are among those most affected by sperm (Lopez-Ubeda et al., 2015). In the sow, there is evidence that the ovary has a local effect on the transcriptome of the oviduct. Unilateral ovariectomy reduces expression of genes believed to be involved in sperm survival and early embryonic development (LopezUbeda et al., 2016). The effect of sperm on the sperm reservoir appears conserved between birds and mammals. Infiltration of porcine sperm into the UTJ and rooster sperm into the chicken utero-vaginal junction alters the expression of genes involved in $\mathrm{pH}$ regulation and immune-modulation (Atikuzzaman et al., 2017). Even more surprisingly, the transcriptional response of oviduct cells is different in response to insemination of either $X$ chromosome- or $Y$ chromosome-bearing sperm (Alminana et al., 2014). Thus, the presence of sperm changes the behavior of oviduct cells in addition to its consequences for sperm. The result of altered production of specific proteins by oviduct cells is not clear.

\section{Sperm release from oviduct epithelial cells}

For successful fertilization, sperm must be released from the reservoir in the isthmus to meet the oocyte in the ampulla. There are several hypotheses to explain how sperm are released. The first is that a signal, perhaps from follicular fluid or the ovulated cumulus-oocyte complex stimulates the release of sperm. This would assure that some sperm are released at the appropriate time. An alternate hypothesis is that a small fraction of sperm is released almost continuously so that there is always a small number of sperm prepared to fertilize an oocyte. It is possible that both mechanisms exist; that is, release in response to a signal is superimposed on top of the more spontaneous release of fractions of sperm. In any case, sperm release is due to a change in sperm behavior, in oviduct cell function or in the oviduct fluid surrounding the cells.

An important maturation that sperm complete in the oviduct is capacitation. After capacitation, sperm have a reduced ability to bind oviduct glycans (Kadirvel et al., 2012; Machado et al., 2014), supporting the hypothesis that during capacitation, glycan receptors are modified. How capacitation might affect glycan receptors is unclear, but there is some preliminary evidence in cattle and swine that, during capacitation, they may be targeted for proteolysis. The molecular mass of one of the BSPs is altered during capacitation (Hung and Suarez, 2012). Furthermore, a candidate glycan receptor on porcine sperm, MFG-E8, co-precipitates in sperm lysates with a proteasomal subunit suggesting it may also be degraded (Miles et al., 2013).
Another alternative is that the development of hyperactivated motility may be sufficient to detach a sperm from the oviduct epithelium (Curtis et al., 2012). In support of this, mouse sperm deficient in CatSper calcium channels that cannot hyperactivate do not detach from the oviduct (Ho et al., 2009).

There is evidence that the cumulus cells of the ovulated cumulus-oocyte complex can release chemical signals, such as progesterone (Schoenfelder et al., 2003; Tosca et al., 2007), which might activate localized sperm release by promoting $\mathrm{Ca}^{2+}$ influx through CatSper channels (Lishko et al., 2012). Release may also be controlled by components from the oviduct itself, such as disulfide reducants (Talevi et al., 2007; Brussow et al., 2008), glycosidases that cleave oviduct glycans from the epithelium (Carrasco et al., 2008a and 2008b), and oviduct smooth muscle contractions (Chang and Suarez, 2012). There is evidence that locally produced anandamide activates cannabinoid receptors and TRPV1 to induce a $\mathrm{Ca}^{2+}$ influx and sperm release (Gervasi et al., 2016). Anandamide may also activate nitric oxide production by sperm to promote their release (Osycka-Salut et al., 2012). Finally, the production of unknown sulfated glyconjugates may release sperm by competing for binding sites on the oviduct epithelium (Talevi and Gualtieri, 2010). The dynamic nature of sperm interaction with the oviduct suggests that a variety of factors may regulate sperm release that may aid in providing a constant supply of competent fertilizing sperm.

\section{Immunological tolerance of sperm in the oviduct}

The oviduct lumen must maintain an aseptic state for successful fertilization and early embryonic development while regulating maternal responses to allogenic sperm and semiallogenic embryos (Marey et al., 2016). Under pathologic conditions, the mucosal immune system produces a proinflammatory response. However, bovine sperm binding to oviduct epithelial cells induces an upregulation of $I L-10$, TGF $\beta$ and increased production of prostaglandin $\mathrm{E}_{2}$, inducing an anti-inflammatory response (Marey et al., 2016; Yousef et al., 2016). This produces an environment that suppresses sperm phagocytosis by PMNs and allows sperm greater opportunity to survive in the oviduct and fertilize oocytes. In essence, sperm induce their own protection from an immune response in the oviduct.

\section{Practical applications}

Sperm reservoirs have a remarkable ability to prolong the viability of sperm and, if we can understand how that is accomplished, we may be able to modify sperm diluents to lengthen sperm lifespan outside of the oviduct (McGetrick et al., 2014). Being able to store bovine sperm for several days would be advantageous in regions of the world where liquid nitrogen is not available or where fresh semen is used routinely due to short transportation times before use (Vishwanath and Shannon, 2000). There is already some evidence that addition of an oviduct protein can improve viability or bovine, porcine and caprine sperm after a 24-48 $\mathrm{h}$ 
incubation (Elliott et al., 2009; Lloyd et al., 2009 and 2012; Holt et al., 2015).

There is also another important application of this research, development of a method to increase sperm lifespan in the oviduct. If sperm survived longer after insemination or natural mating, cows that ovulated well after semen deposition would have a higher likelihood of pregnancy. This might reduce the requirement for frequent estrus detection in females because a precise estimate of ovulation time might not be as crucial. Fertility despite the uncoupling of mating with ovulation has been accomplished by some mammals, notably some species of bats that store sperm for months, as well as snakes, reptiles and insects (Holt and Fazeli, 2016). Although the opportunity to reduce estrus detection by lengthening sperm lifespan may be overly optimistic, the examples in nature of species that store sperm for a long duration suggest that it may be possible.

\section{Acknowledgments}

Work in the author's laboratory was supported by Agriculture and Food Research Initiative Competitive Grant No. 2011-6701520099 and 2015-67015-23228 from the USDA National Institute of Food and Agriculture and the National Science Foundation. The author acknowledges Rebecca Winters and Lantana Grub for comments that improved the manuscript and apologizes for being unable to discuss other important work due to length restrictions.

\section{Declaration of interest}

The author has no conflict of interest.

\section{Ethics Statement}

None of the original studies described herein by the author used live animals.

\section{Software and Data Repository Resources}

Glycan array data are deposited with the Center for Functional Glycomics, which is publicly available.

\section{References}

Abe H, Sendai Y, Satoh T and Hoshi H 1995. Bovine oviduct-specific glycoprotein: a potent factor for maintenance of viability and motility of bovine spermatozoa in vitro. Molecular Reproduction and Development 42, 226-232.

Alasmari W, Costello S, Correia J, Oxenham SK, Morris J, Fernandes L, RamalhoSantos J, Kirkman-Brown J, Michelangeli F, Publicover S and Barratt CL 2013. $\mathrm{Ca} 2+$ signals generated by catsper and $\mathrm{ca} 2+$ stores regulate different behaviors in human sperm. Journal of Biological Chemistry 288, 6248-6258.

Al-Dossary AA, Bathala P, Caplan JL and Martin-DeLeon PA 2015. Oviductosome-sperm membrane interaction in cargo delivery: detection of fusion and underlying molecular players using three-dimensional super-resolution structured illumination microscopy (sr-sim). Journal of Biological Chemistry 290, 17710-17723.

Algarra B, Han L, Soriano-Ubeda C, Aviles M, Coy P, Jovine L and JimenezMovilla M 2016. The c-terminal region of ovgp1 remodels the zona pellucida and modifies fertility parameters. Scientific Reports 6, 32556.

Alminana C, Caballero I, Heath PR, Maleki-Dizaji S, Parrilla I, Cuello C, Gil MA, Vazquez JL, Vazquez JM, Roca J, Martinez EA, Holt WV and Fazeli A 2014. The battle of the sexes starts in the oviduct: modulation of oviductal transcriptome by $x$ and $y$-bearing spermatozoa. BMC Genomics 15, 293.
Amann RP and Griel LC Jr. 1974. Fertility of bovine spermatozoa from rete testis, cauda epididymidis, and ejaculated semen. Journal of Dairy Science 57, 212-219.

Araki Y, Nohara M, Yoshida-Komiya H, Kuramochi T, Ito M, Hoshi H, Shinkai Y and Sendai $Y$ 2003. Effect of a null mutation of the oviduct-specific glycoprotein gene on mouse fertilization. Biochemical Journal 374, 551-557.

Atikuzzaman M, Alvarez-Rodriguez M, Vicente-Carrillo A, Johnsson M, Wright D and Rodriguez-Martinez $\mathrm{H}$ 2017. Conserved gene expression in sperm reservoirs between birds and mammals in response to mating. BMC Genomics 18, 98.

Bergqvist AS, Ballester J, Johannisson A, Hernandez $M$, Lundeheim N and Rodriguez-Martinez H 2006. In vitro capacitation of bull spermatozoa by oviductal fluid and its components. Zygote 14, 259-273.

Bergqvist AS, Yokoo M, Bage R, Sato E and Rodriguez-Martinez H 2005a. Detection of the hyaluronan receptor $\mathrm{cd} 44$ in the bovine oviductal epithelium. Journal of Reproduction and Development 51, 445-453.

Bergqvist AS, Yokoo M, Heldin P, Frendin J, Sato E and Rodriguez-Martinez H 2005b. Hyaluronan and its binding proteins in the epithelium and intraluminal fluid of the bovine oviduct. Zygote 13, 207-218.

Boilard M, Bailey J, Collin S, Dufour M and Sirard MA 2002. Effect of bovine oviduct epithelial cell apical plasma membranes on sperm function assessed by a novel flow cytometric approach. Biology of Reproduction 67, 1125-1132.

Boilard M, Reyes-Moreno C, Lachance C, Massicotte L, Bailey JL, Sirard MA and Leclerc P 2004. Localization of the chaperone proteins grp78 and hsp60 on the luminal surface of bovine oviduct epithelial cells and their association with spermatozoa. Biology of Reproduction 71, 1879-1889.

Bromfield JJ 2014. Seminal fluid and reproduction: much more than previously thought. Journal of Assisted Reproduction and Genetics 31, 627-636.

Bromfield JJ, Schjenken JE, Chin PY, Care AS, Jasper MJ and Robertson SA 2014. Maternal tract factors contribute to paternal seminal fluid impact on metabolic phenotype in offspring. Proceedings of the National Academy of Sciences United States of America 111, 2200-2205.

Brussow KP, Ratky J and Rodriguez-Martinez H 2008. Fertilization and early embryonic development in the porcine fallopian tube. Reproduction in Domestic Animals 43 (suppl. 2), 245-251.

Caballero JN, Gervasi MG, Veiga MF, Dalvit GC, Perez-Martinez S, Cetica PD and Vazquez-Levin MH 2014. Epithelial cadherin is present in bovine oviduct epithelial cells and gametes, and is involved in fertilization-related events. Theriogenology 81, 1189-1206.

Carrasco LC, Coy P, Aviles M, Gadea J and Romar R 2008a. Glycosidase determination in bovine oviducal fluid at the follicular and luteal phases of the oestrous cycle. Reproduction Fertility and Development 20, 808-817.

Carrasco LC, Romar R, Aviles M, Gadea J and Coy P 2008b. Determination of glycosidase activity in porcine oviductal fluid at the different phases of the estrous cycle. Reproduction 136, 833-842.

Chang $\mathrm{H}$ and Suarez SS 2012. Unexpected flagellar movement patterns and epithelial binding behavior of mouse sperm in the oviduct. Biology of Reproduction 86, 140.

Christoffersen M and Troedsson M 2017. Inflammation and fertility in the mare. Reproduction in Domestic Animals 52 (suppl. 3), 14-20.

Cortes PP, Orihuela PA, Zuniga LM, Velasquez LA and Croxatto HB 2004. Sperm binding to oviductal epithelial cells in the rat: role of sialic acid residues on the epithelial surface and sialic acid-binding sites on the sperm surface. Biology of Reproduction 71, 1262-1269.

Coy P, Lloyd R, Romar R, Satake N, Matas C, Gadea J and Holt WV 2010. Effects of porcine pre-ovulatory oviductal fluid on boar sperm function. Theriogenology 74, 632-642.

Curtis MP, Kirkman-Brown JC, Connolly TJ and Gaffney EA 2012. Modelling a tethered mammalian sperm cell undergoing hyperactivation. Journal of Theoretical Biology 309C, 1-10.

DeJarnette JM, Nebel RL and Marshall CE 2009. Evaluating the success of sexsorted semen in us dairy herds from on farm records. Theriogenology 71, 49-58. Demott RP and Suarez SS 1992. Hyperactivated sperm progress in the mouse oviduct. Biology of Reproduction 46, 779-785.

Denissenko P, Kantsler V, Smith DJ and Kirkman-Brown J 2012. Human spermatozoa migration in microchannels reveals boundary-following navigation. Proceedings of the National Academy of Sciences United States of America 109, 8007-8010. 
Dobrinski I, Ignotz GG, Thomas PG and Ball BA 1996. Role of carbohydrates in the attachment of equine spermatozoa to uterine tubal (oviductal) epithelial cells in vitro. American Journal of Veterinary Research 57, 1635-1639.

Dobrinski I, Smith TT, Suarez SS and Ball BA 1997. Membrane contact with oviductal epithelium modulates the intracellular calcium concentration of equine spermatozoa in vitro. Biology of Reproduction 56, 861-869.

Ekhlasi-Hundrieser M, Gohr K, Wagner A, Tsolova M, Petrunkina A and TopferPetersen E 2005. Spermadhesin aqn1 is a candidate receptor molecule involved in the formation of the oviductal sperm reservoir in the pig. Biology of Reproduction 73, 536-545.

Elliott RM, Lloyd RE, Fazeli A, Sostaric E, Georgiou AS, Satake N, Watson PF and Holt WV 2009. Effects of hspa8, an evolutionarily conserved oviductal protein on boar and bull spermatozoa. Reproduction 137, 191-203.

El-Sherry TM, Elsayed M, Abdelhafez HK and Abdelgawad M 2014. Characterization of rheotaxis of bull sperm using microfluidics. Integrative Biology (Cambridge) 6, 1111-1121.

Erikson DW, Way AL, Chapman DA and Killian GJ 2007. Detection of osteopontin on holstein bull spermatozoa, in cauda epididymal fluid and testis homogenates, and its potential role in bovine fertilization. Reproduction 133, 909-917.

Evans RW and Setchell BP 1978. Association of exogenous phospholipids with spermatozoa. Journal of Reproduction and Fertility 53, 357-362.

Fazeli A, Affara NA, Hubank M and Holt WV 2004. Sperm-induced modification of the oviductal gene expression profile after natural insemination in mice. Biology of Reproduction 71, 60-65.

Fazeli A, Elliott RM, Duncan AE, Moore A, Watson PF and Holt WV 2003. In vitro maintenance of boar sperm viability by a soluble fraction obtained from oviductal apical plasma membrane preparations. Reproduction 125, 509-517. Georgiou AS, Snijders AP, Sostaric E, Aflatoonian R, Vazquez JL, Vazquez JM, Roca J, Martinez EA, Wright PC and Fazeli A 2007. Modulation of the oviductal environment by gametes. Journal of Proteome Research 6, 4656-4666.

Georgiou AS, Sostaric E, Wong CH, Snijders AP, Wright PC, Moore HD and Fazeli A 2005. Gametes alter the oviductal secretory proteome. Molecular and Cellular Proteomics 4, 1785-1796.

Gervasi MG, Osycka-Salut C, Sanchez T, Alonso CA, Llados C, Castellano L, Franchi AM, Villalon M and Perez-Martinez S 2016. Sperm release from the oviductal epithelium depends on $\mathrm{ca}(2+)$ influx upon activation of $\mathrm{cb} 1$ and trpv1 by anandamide. Journal of Cellular Biochemistry 117, 320-333.

Goncalves RF, Chapman DA, Bertolla RP, Eder I and Killian GJ 2008. Pre-treatment of cattle semen or oocytes with purified milk osteopontin affects in vitro fertilization and embryo development. Animal Reproduction Science 108, 375-383.

Gonzalez-Abreu D, Garcia-Martinez S, Fernandez-Espin V, Romar R and Gadea J 2017. Incubation of boar spermatozoa in viscous media by addition of methylcellulose improves sperm quality and penetration rates during in vitro fertilization. Theriogenology 92, 14-23.

Green CE, Bredl J, Holt WV, Watson PF and Fazeli A 2001. Carbohydrate mediation of boar sperm binding to oviductal epithelial cells in vitro. Reproduction 122, 305-315.

Hansen PJ 2011. The immunology of early pregnancy in farm animals. Reproduction in Domestic Animals 46 (suppl. 3), 18-30.

Hawk HW 1987. Transport and fate of spermatozoa after insemination of cattle. Journal of Dairy Science 70, 1487-1503.

Ho K, Wolff CA and Suarez SS 2009. Catsper-null mutant spermatozoa are unable to ascend beyond the oviductal reservoir. Reproduction Fertility and Development 21, 345-350.

Holt WV, Del Valle I and Fazeli A 2015. Heat shock protein a8 stabilizes the bull sperm plasma membrane during cryopreservation: effects of breed, protein concentration, and mode of use. Theriogenology 84, 693-701.

Holt WV and Fazeli A 2016. Sperm storage in the female reproductive tract. Annual Reviews in Animal Biosciences 4, 291-310.

Hung PH and Suarez SS 2010. Regulation of sperm storage and movement in the ruminant oviduct. Society for Reproduction and Fertility Supplement 67, 257-266.

Hung PH and Suarez SS 2012. Alterations to the bull sperm surface proteins that bind sperm to oviductal epithelium. Biology of Reproduction 87, 88.

Hunter RH 1995. Significance of the epithelial crypts at the bovine utero-tubal junction in the pre-ovulatory phase of sperm regulation. Acta Veterinaria Scandinavica 36, 413-421.
Hunter RH 2002. Vital aspects of fallopian tube physiology in pigs. Reproduction in Domestic Animals 37, 186-190.

Hunter RH and Leglise PC 1971. Polyspermic fertilization following tubal surgery in pigs, with particular reference to the role of the isthmus. Journal of Reproduction and Fertility 24, 233-246.

Hunter RH, Nichol R and Crabtree SM 1980. Transport of spermatozoa in the ewe: timing of the establishment of a functional population in the oviduct. Reproduction Nutrition and Development 20, 1869-1875.

Hyakutake T, Suzuki H and Yamamoto S 2015. Effect of non-Newtonian fluid properties on bovine sperm motility. Journal of Biomechanics 48, 2941-2947.

Ignotz GG, Cho MY and Suarez SS 2007. Annexins are candidate oviductal receptors for bovine sperm surface proteins and thus may serve to hold bovine sperm in the oviductal reservoir. Biology of Reproduction 77, 906-913.

Ishikawa Y, Usui T, Yamashita M, Kanemori Y and Baba T 2016. Surfing and swimming of ejaculated sperm in the mouse oviduct. Biology of Reproduction $94,89$.

Jaffe RC, Arias EB, O'Day-Bowman MB, Donnelly KM, Mavrogianis PA and Verhage HG 1996. Regional distribution and hormonal control of estrogendependent oviduct-specific glycoprotein messenger ribonucleic acid in the baboon (papio anubis). Biology of Reproduction 55, 421-426.

Jansen RP 1978. Fallopian tube isthmic mucus and ovum transport. Science 201 349-351.

Jin M, Fujiwara E, Kakiuchi Y, Okabe M, Satouh Y, Baba SA, Chiba K and Hirohashi N 2011. Most fertilizing mouse spermatozoa begin their acrosome reaction before contact with the zona pellucida during in vitro fertilization. Proceedings of the National Academy of Sciences United States of America 108, 4892-4896.

Kadirvel G, Machado SA, Korneli C, Collins E, Miller P, Bess KN, Aoki K, Tiemeyer M, Bovin N and Miller DJ 2012. Porcine sperm bind to specific 6-sialylated biantennary glycans to form the oviduct reservoir. Biology of Reproduction 87, 147.

Katila T 2012. Post-mating inflammatory responses of the uterus. Reproduction in Domestic Animals 47 (suppl. 5), 31-41.

Katz DF, Slade DA and Nakajima ST 1997. Analysis of pre-ovulatory changes in cervical mucus hydration and sperm penetrability. Advances in Contraception $13,143-151$

Kawano N, Araki N, Yoshida K, Hibino T, Ohnami N, Makino M, Kanai S, Hasuwa H, Yoshida M, Miyado K and Umezawa A 2014. Seminal vesicle protein svs2 is required for sperm survival in the uterus. Proceedings of the National Academy of Sciences United States of America 111, 4145-4150.

Kervancioglu ME, Saridogan E, Aitken RJ and Djahanbakhch 0 2000. Importance of sperm-to-epithelial cell contact for the capacitation of human spermatozoa in fallopian tube epithelial cell cocultures. Fertility and Sterility 74, 780-784.

Killian G 2011. Physiology and endocrinology symposium: evidence that oviduct secretions influence sperm function: a retrospective view for livestock. Journal of Animal Science 89, 1315-1322.

Killian GJ, Chapman DA, Kavanaugh JF, Deaver DR and Wiggin HB 1989. Changes in phospholipids, cholesterol and protein content of oviduct fluid of cows during the oestrous cycle. Journal of Reproduction and Fertility 86, 419-426.

Kirkman-Brown JC and Smith DJ 2011. Sperm motility: is viscosity fundamental to progress? Molecular and Human Reproduction 17, 539-544.

Kunz G, Beil D, Deininger H, Wildt L and Leyendecker G 1996. The dynamics of rapid sperm transport through the female genital tract: evidence from vaginal sonography of uterine peristalsis and hysterosalpingoscintigraphy. Human Reproduction 11, 627-632.

Kutteh WH, Prince SJ, Hammond KR, Kutteh CC and Mestecky J 1996. Variations in immunoglobulins and $\operatorname{lgA}$ subclasses of human uterine cervical secretions around the time of ovulation. Clinical and Experimental Immunology 104, 538-542.

Lamy J, Labas V, Harichaux G, Tsikis G, Mermillod P and Saint-Dizier M 2016. Regulation of the bovine oviductal fluid proteome. Reproduction 152, 629-644. Lapointe J and Bilodeau JF 2003. Antioxidant defenses are modulated in the cow oviduct during the estrous cycle. Biology of Reproduction 68, 1157-1164.

La Spina FA, Puga Molina LC, Romarowski A, Vitale AM, Falzone TL, Krapf D, Hirohashi N and Buffone MG 2016. Mouse sperm begin to undergo acrosomal exocytosis in the upper isthmus of the oviduct. Developmental Biology 411 172-182. 
Lefebvre R, Chenoweth PJ, Drost M, LeClear CT, MacCubbin M, Dutton JT and Suarez SS 1995. Characterization of the oviductal sperm reservoir in cattle. Biology of Reproduction 53, 1066-1074.

Lefebvre R, Lo MC and Suarez SS 1997. Bovine sperm binding to oviductal epithelium involves fucose recognition. Biology of Reproduction 56, 1198-1204.

Lishko PV, Kirichok Y, Ren D, Navarro B, Chung JJ and Clapham DE 2012. The control of male fertility by spermatozoan ion channels. Annual Reviews in Physiology 74, 453-475.

Lloyd RE, Elliott RM, Fazeli A, Watson PF and Holt WV 2009. Effects of oviductal proteins, including heat shock 70 kda protein 8 , on survival of ram spermatozoa over $48 \mathrm{~h}$ in vitro. Reproduction Fertility and Development 21 , 408-418.

Lloyd RE, Fazeli A, Watson PF and Holt WV 2012. The oviducal protein, heatshock 70-kda protein 8 , improves the long-term survival of ram spermatozoa during storage at 17 degrees $\mathrm{c}$ in a commercial extender. Reproduction Fertility and Development 24, 543-549.

Lopez-Ubeda R, Garcia-Vazquez FA, Romar R, Gadea J, Munoz M, Hunter RH and Coy P 2015. Oviductal transcriptome is modified after insemination during spontaneous ovulation in the sow. PLoS One 10, e0130128.

Lopez-Ubeda R, Munoz M, Vieira L, Hunter RH, Coy P and Canovas S 2016. The oviductal transcriptome is influenced by a local ovarian effect in the sow. Journal of Ovarian Research 9, 44.

Lovell JW and Getty R 1968. Fate of semen in the uterus of the sow: histologic study of endometrium during the 27 hours after natural service. American Journal of Veterinary Research 29, 609-625.

Lyng R and Shur BD 2009. Mouse oviduct-specific glycoprotein is an eggassociated zp3-independent sperm-adhesion ligand. Journal of Cell Science 122 , 3894-3906.

Machado SA, Kadirvel G, Daigneault BW, Korneli C, Miller P, Bovin N and Miller DJ 2014. Lewisx-containing glycans on the porcine oviductal epithelium contribute to formation of the sperm reservoir. Biology of Reproduction 91, 140.

Marey MA, Yousef MS, Kowsar R, Hambruch N, Shimizu T, Pfarrer C and Miyamoto A 2016. Local immune system in oviduct physiology and pathophysiology: attack or tolerance? Domestic Animal Reproduction 56 (suppl.), S204-S211.

Mathur S, Rosenlund C, Carlton M, Caldwell J, Barber M, Rust PF and Williamson HO 1988. Studies on sperm survival and motility in the presence of cytotoxic sperm antibodies. American Journal of Reproductive Immunology and Microbiology 17, 41-47.

McGetrick JA, Reid CJ and Carrington SD 2014. Improving bovine semen diluents: insights from the male and female reproductive tracts, and the potential relevance of cervical mucins. Animal 8 (suppl. 1), 173-184.

Miki $\mathrm{K}$ and Clapham DE 2013. Rheotaxis guides mammalian sperm. Current Biology 23, 443-452.

Miles EL, O'Gorman C, Zhao J, Samuel M, Walters E, Yi YJ, Sutovsky M, Prather RS, Wells KD and Sutovsky P 2013. Transgenic pig carrying green fluorescent proteasomes. Proceedings of the National Academy of Sciences United States of America 110, 6334-6339.

Moore SG and Hasler JF 2017. A 100-year review: reproductive technologies in dairy science. Journal of Dairy Science 100, 10314-10331.

Mullins KJ and Saacke RG 1989. Study of the functional anatomy of bovine cervical mucosa with special reference to mucus secretion and sperm transport. Anatomical Record 225, 106-117.

Muro Y, Hasuwa H, Isotani A, Miyata H, Yamagata K, Ikawa M, Yanagimachi R and Okabe M 2016. Behavior of mouse spermatozoa in the female reproductive tract from soon after mating to the beginning of fertilization. Biology of Reproduction 94, 80.

Murray SC and Smith TT 1997. Sperm interaction with fallopian tube apical membrane enhances sperm motility and delays capacitation. Fertility and Sterility $68,351-357$.

Naito $Y$, Takematsu H, Koyama S, Miyake S, Yamamoto H, Fujinawa R, Sugai M, Okuno Y, Tsujimoto G, Yamaji T, Hashimoto Y, Itohara S, Kawasaki T, Suzuki A and Kozutsumi $Y$ 2007. Germinal center marker gl7 probes activation-dependent repression of n-glycolylneuraminic acid, a sialic acid species involved in the negative modulation of b-cell activation. Molecular and Cellular Biology 27, 3008-3022.

Nakanishi T, Isotani A, Yamaguchi R, Ikawa M, Baba T, Suarez SS and Okabe M 2004. Selective passage through the uterotubal junction of sperm from a mixed population produced by chimeras of calmegin-knockout and wild-type male mice. Biology of Reproduction 71, 959-965.

Okabe M 2013. The cell biology of mammalian fertilization. Development 140, 4471-4479.

Orr TJ and Zuk M 2014. Reproductive delays in mammals: an unexplored avenue for post-copulatory sexual selection. Biological Reviews of the Cambridge Philosophical Society 89, 889-912.

Osycka-Salut C, Gervasi MG, Pereyra E, Cella M, Ribeiro ML, Franchi AM and Perez-Martinez S 2012. Anandamide induces sperm release from oviductal epithelia through nitric oxide pathway in bovines. PLoS One 7, e30671.

Osycka-Salut CE, Castellano L, Fornes D, Beltrame JS, Alonso CAl, Jawerbaum A, Franchi A, Diaz ES and Perez Martinez S 2017. Fibronectin from oviductal cells fluctuates during the estrous cycle and contributes to sperm-oviduct interaction in cattle. Journal of Cellular Biochemistry 118, 4095-4108.

Pacey AA, Hill CJ, Scudamore IW, Warren MA, Barratt CL and Cooke ID 1995. The interaction in vitro of human spermatozoa with epithelial cells from the human uterine (fallopian) tube. Human Reproduction 10, 360-366.

Parrish JJ, Susko-Parrish JL, Handrow RR, Sims MM and First NL 1989. Capacitation of bovine spermatozoa by oviduct fluid. Biology of Reproduction 40, 1020-1025.

Petrunkina AM, Gehlhaar R, Drommer W, Waberski D and Topfer-Petersen E 2001. Selective sperm binding to pig oviductal epithelium in vitro. Reproduction $121,889-896$.

Pillai VV, Weber DM, Phinney BS and Selvaraj V 2017. Profiling of proteins secreted in the bovine oviduct reveals diverse functions of this luminal microenvironment. PLoS One 12, e0188105.

Pollard JW, Plante C, King WA, Hansen PJ, Betteridge KJ and Suarez SS 1991. Fertilizing capacity of bovine sperm may be maintained by binding of oviductal epithelial cells. Biology of Reproduction 44, 102-107.

Rath D, Knorr C and Taylor U 2016. Communication requested: boar semen transport through the uterus and possible consequences for insemination. Theriogenology 85, 94-104.

Rijsselaere T, Van Soom A, Van Cruchten S, Coryn M, Gortz K, Maes D and de Kruif A 2004. Sperm distribution in the genital tract of the bitch following artificial insemination in relation to the time of ovulation. Reproduction 128, 801-811.

Rittling SR, Matsumoto HN, McKee MD, Nanci A, An XR, Novick KE, Kowalski AJ, Noda M and Denhardt DT 1998. Mice lacking osteopontin show normal development and bone structure but display altered osteoclast formation in vitro. Journal of Bone and Mineral Research 13, 1101-1111.

Robertson SA 2007. Seminal fluid signaling in the female reproductive tract: lessons from rodents and pigs. Journal of Animal Science 85, E36-E44.

Rodriguez-Martinez H 2007. Role of the oviduct in sperm capacitation. Theriogenology 68 (suppl. 1), S138-S146.

Rodriguez-Martinez $H$, Saravia $F$, Wallgren $M$, Tienthai $P$, Johannisson $A$, Vazquez JM, Martinez E, Roca J, Sanz L and Calvete JJ 2005. Boar spermatozoa in the oviduct. Theriogenology 63, 514-535.

Rutllant J, Lopez-Bejar M and Lopez-Gatius F 2005. Ultrastructural and rheological properties of bovine vaginal fluid and its relation to sperm motility and fertilization: a review. Reproduction in Domestic Animals 40, 79-86.

Sanz L, Calvete JJ, Mann K, Gabius HJ and Topfer-Petersen E 1993. Isolation and biochemical characterization of heparin-binding proteins from boar seminal plasma: a dual role for spermadhesins in fertilization. Molecular Reproduction and Development 35, 37-43.

Schjenken JE and Robertson SA 2014. Seminal fluid and immune adaptation for pregnancy - comparative biology in mammalian species. Reproduction in Domestic Animals 49 (suppl. 3), 27-36.

Schjenken JE and Robertson SA 2015. Seminal fluid signalling in the female reproductive tract: implications for reproductive success and offspring health. Advances in Experimental Medicine and Biology 868, 127-158.

Schoenfelder M, Schams D and Einspanier R 2003. Steroidogenesis during in vitro maturation of bovine cumulus oocyte complexes and possible effects of tri-butyltin on granulosa cells. Journal of Steroid Biochemistry and Molecular Biology 84, 291-300.

Silva E, Frost D, Li L, Bovin N and Miller DJ 2017. Lactadherin is a candidate oviduct Lewis $\mathrm{x}$ trisaccharide receptor on porcine spermatozoa. Andrology 5 , 589-597. 
Silva E, Kadirvel G, Jiang R, Bovin N and Miller D 2014. Multiple proteins from ejaculated and epididymal porcine spermatozoa bind glycan motifs found in the oviduct. Andrology 2, 763-771.

Smith TT and Nothnick WB 1997. Role of direct contact between spermatozoa and oviductal epithelial cells in maintaining rabbit sperm viability. Biology of Reproduction 56, 83-89.

Song $\mathrm{X}$, Yu H, Chen X, Lasanajak Y, Tappert MM, Air GM, Tiwari VK, Cao H Chokhawala HA, Zheng H, Cummings RD and Smith DF 2011. A sialylated glycan microarray reveals novel interactions of modified sialic acids with proteins and viruses. Journal of Biological Chemistry 286, 31610-31622.

Suarez S, Redfern K, Raynor P, Martin F and Phillips DM 1991. Attachment of boar sperm to mucosal explants of oviduct in vitro: possible role in formation of a sperm reservoir. Biology of Reproduction 44, 998-1004.

Suarez SS 2001. Carbohydrate-mediated formation of the oviductal sperm reservoir in mammals. Cells Tissues and Organs 168, 105-112.

Suarez SS, Brockman K and Lefebvre R 1997. Distribution of mucus and sperm in bovine oviducts after artificial insemination: the physical environment of the oviductal sperm reservoir. Biology of Reproduction 56, 447-453.

Suarez SS and Dai X 1992. Hyperactivation enhances mouse sperm capacity for penetrating viscoelastic media. Biology of Reproduction 46, 686-691.

Suarez SS and Pacey AA 2006. Sperm transport in the female reproductive tract. Human Reproduction Update 12, 23-37.

Suarez SS, Revah I, Lo M and Kolle S 1998. Bull sperm binding to oviductal epithelium is mediated by a ca2 +-dependent lectin on sperm that recognizes Lewis-a trisaccharide. Biology of Reproduction 59, 39-44.

Talevi R and Gualtieri R 2010. Molecules involved in sperm-oviduct adhesion and release. Theriogenology 73, 796-801.

Talevi R, Zagami M, Castaldo M and Gualtieri R 2007. Redox regulation of sperm surface thiols modulates adhesion to the fallopian tube epithelium. Biology of Reproduction 76, 728-735.

Teijeiro JM, Dapino DG and Marini PE 2011. Porcine oviduct sperm binding glycoprotein and its deleterious effect on sperm: a mechanism for negative selection of sperm? Biological Research 44, 329-337.

Teijeiro JM and Marini PE 2012. Apical membranes prepared by peeling from whole porcine oviducts interact with homologous sperm. Cell and Tissue Research 348, 213-223.

Tienthai $P$ 2015. The porcine sperm reservoir in relation to the function of hyaluronan. Journal of Reproduction and Develoment 61, 245-250.
Topfer-Petersen E, Ekhlasi-Hundrieser M and Tsolova M 2008. Glycobiology of fertilization in the pig. International Journal of Developmental Biology 52, 717-736.

Tosca L, Uzbekova S, Chabrolle C and Dupont J 2007. Possible role of 5'ampactivated protein kinase in the metformin-mediated arrest of bovine oocytes at the germinal vesicle stage during in vitro maturation. Biology of Reproduction $77,452-465$.

Tung CK, Ardon F, Roy A, Koch DL, Suarez SS and Wu M 2015a. Emergence of upstream swimming via a hydrodynamic transition. Physical Review Letters 114, 108102.

Tung CK, Hu L, Fiore AG, Ardon F, Hickman DG, Gilbert RO, Suarez SS and Wu M 2015b. Microgrooves and fluid flows provide preferential passageways for sperm over pathogen tritrichomonas foetus. Proceedings of the National Academy of Sciences United States of America 112, 5431-5436.

Tung CK, Lin C, Harvey B, Fiore AG, Ardon F, Wu M and Suarez SS 2017. Fluid viscoelasticity promotes collective swimming of sperm. Scientific Reports 7, 3152.

Tyler KR 1977. Histological changes in the cervix of the rabbit after coitus. Journal of Reproduction and Fertility 49, 341-345.

Vishwanath R and Shannon P 2000. Storage of bovine semen in liquid and frozen state. Animal Reproduction Science 62, 23-53.

Wilmut I and Hunter RH 1984. Sperm transport into the oviducts of heifers mated early in oestrus. Reproduction Nutrition and Development 24, 461-468. Wrobel KH, Kujat R and Fehle G 1993. The bovine tubouterine junction: general organization and surface morphology. Cell and Tissue Research 271, 227-239.

Yamaguchi R, Muro Y, Isotani A, Tokuhiro K, Takumi K, Adham I, Ikawa M and Okabe M 2009. Disruption of adam3 impairs the migration of sperm into oviduct in mouse. Biology of Reproduction 81, 142-146.

Yamaguchi R, Yamagata K, Ikawa M, Moss SB and Okabe M 2006. Aberrant distribution of adam3 in sperm from both angiotensin-converting enzyme (ace)- and calmegin (clgn)-deficient mice. Biology of Reproduction 75, 760-766.

Yang $X$, Zhao $Y$, Yang X and Kan FW 2015. Recombinant hamster oviductin is biologically active and exerts positive effects on sperm functions and spermoocyte binding. PLoS One 10, e0123003.

Yousef MS, Marey MA, Hambruch N, Hayakawa H, Shimizu T, Hussien HA, Abdel-Razek AK, Pfarrer C and Miyamoto A 2016. Sperm binding to oviduct epithelial cells enhances tgfb1 and il10 expressions in epithelial cells as well as neutrophils in vitro: prostaglandin e2 as a main regulator of anti-inflammatory response in the bovine oviduct. PLoS One 11, e0162309. 